\title{
SAHARAN DUST EVENTS OVER THE NORTHERN MEDITERRANEAN: 4 YEARS OF MEASUREMENTS OVER 4 EARLINET STATIONS
}

\author{
Ourania Soupiona $^{1^{*}}$, Alex Papayannis ${ }^{1}$, Maria Mylonaki ${ }^{1}$, Nikolaos Papagiannopoulos ${ }^{2}$, Pablo Ortiz- \\ Amezcua $^{3,4}$, Rodanthi E. Mamouri ${ }^{5}$, Silke Groß ${ }^{6}$, Christina A. Papanikolaou ${ }^{1}$, Panagiotis Kokkalis ${ }^{7}$ \\ ${ }^{1}$ Applied Mathematics and Physical Sciences, National Technical University of Athens, 15780, Greece \\ ${ }^{2}$ Consiglio Nazionale delle Ricerche, Istituto di Metodologie per l'Analisi Ambientale, Tito Scalo, 85050, Italy. \\ ${ }^{3}$ Andalusian Institute for Earth System Research, 18006, Granada, Spain \\ ${ }^{4}$ Department of Applied Physics, University of Granada, 18071, Granada, Spain \\ ${ }^{5}$ Department of Civil Engineering and Geomatics, ERATOSTHENES Research Centre, Cyprus University of \\ Technology, 3036, Limassol, Cyprus \\ ${ }^{6}$ Institute of Atmospheric Physics, Deutsches Zentrum für Luft- und Raumfahrt (DLR), Oberpfaffenhofen, 82234, \\ Germany \\ ${ }^{7}$ Department of Physics, Kuwait University, P.O. Box 5969, Safat 13060, Kuwait \\ *Email:soupiona.rania@gmail.com
}

\begin{abstract}
Four years (2014-2017) of observations of depolarization Raman Lidar systems of four EARLINET (European Aerosol research Lidar Network) stations [from West to East: Granada (Spain), Potenza (Italy), Athens (Greece) and Limassol (Cyprus)] were collected and used to a statistical analysis of Saharan dust events over Mediterranean basin.

In this study, emphasis is given to the consistency of the particle linear depolarization ratio $\left(\delta_{\mathrm{p} 532}\right)$, the extinction-to-backscatter ratio mentioned as Lidar Ratio $\left(\mathrm{LR}_{532}\right)$ and the Aerosol Optical Thickness $\left(\mathrm{AOT}_{532}\right)$ within the observed Saharan dust layers, corresponding to the visible range $(532 \mathrm{~nm})$. Geometrical properties and clusters of aerosol mixtures are also presented. Our clustering was based on previous classification by airborne High Spectral Resolution Lidar (HSRL) observations and was further supported by backward trajectory analysis. We found mean $\delta_{\mathrm{p} 532}$ values of $0.24 \pm 0.05$, $0.26 \pm 0.06,0.28 \pm 0.05$ and $0.28 \pm 0.04$, mean $L_{532}$ values of $52 \pm 8 \mathrm{sr}, 51 \pm 9 \mathrm{sr}, 52 \pm 9 \mathrm{sr}$ and $49 \pm 6 \mathrm{sr}$, mean $\mathrm{AOT}_{532}$ values of $0.40 \pm 0.31,0.11 \pm 0.07$, $0.12 \pm 0.10$ and $0.32 \pm 0.17$ and mean layer thicknesses of $3392 \pm 1458 \mathrm{~m}, 2150 \pm 1082 \mathrm{~m}, 1872 \pm 816 \mathrm{~m}$ and $1716 \pm 567 \mathrm{~m}$ for Granada, Potenza, Athens and Limassol respectively.

This work could assist in bridging the existing gaps related to the extensive and intensive dust aerosol properties over the Mediterranean and enriching the bibliography about mixed aerosol layers from different sources (e.g. dust and biomass burning (BB) aerosols, dust and urban/ industrial aerosols).
\end{abstract}

\section{INTRODUCTION}

The Mediterranean basin plays a crucial role in different origin air mass cross paths and transitions since it covers portions of three continents: Europe, Asia and Africa. Depending on the season and the area of the observation, dust can originate from different places of the Saharan and Asian region. Desert dust is one of the major natural aerosol sources while Sahara is one of the biggest deserts all over the world.

Saharan dust advections to Mediterranean countries are modulated by meteorology along rather regular seasonal patterns. In the Western Mediterranean (Granada), the African dust occurrence is higher in summer [1]. In Central Mediterranean (Potenza), spring and summer are associated to dust aerosol loads extending up to altitudes of 3-4 km [2]. In Eastern Mediterranean (Athens and Limassol), the main dust transport occurs from spring to autumn [3, $4,5]$ as a result of the high cyclonic activity over northern Africa during this period [6].

Mineral dust may highly influence the atmospheric radiation balance as well as the cloud nucleation, formation and lifetime, through scattering and absorption processes [7]. Considerable uncertainties in quantifying the global direct radiative effects of aerosols arise from the variability of aerosols' spatial distribution and aging/mixing processes that can affect their optical and microphysical properties.

Light detection and ranging (Lidar) instruments are among the most powerful and suitable tools for retrieving vertically the aerosol optical properties with high temporal and spatial resolution $[8,9,10]$. Up to now, there are a lot of studies about Saharan dust optical properties $[3,4,10,11,12]$, however many Lidar stations did not have depolarization sensitive channels until a few years ago, for longterm statistical analysis.

In this study, we introduce the four EARLINET stations and present the data selection and methodology in Section 2. In section 3, we present our results, while in Section 4 our conclusions are shortly presented.

\section{METHODOLOGY}




\subsection{The four EARLINET Lidar systems}

Four EARLINET stations have been considered in this study, as representative of mineral dust events over the Northern Mediterranean basin, due to their location close to the African continent. The corresponding institutes, along with their location and Lidar setup, are presented in Table 1. In order to provide homogeneous Lidar data and results we used a common study period (2014-2017) and the vertical profiles of the $532 \mathrm{~nm}$ backscatter $(\beta)$, extinction $(\alpha)$ and depolarization $(\delta)$ signals, only. Raman-Lidar (nighttime) observations were used in order to provide the $\mathrm{LR}_{532}$, and depolarization (daytime or nighttime) observations were used to provide the $\delta_{\mathrm{p} 532}$.

\subsection{Data selection and analysis}

The total number of dust cases per station for the period 2014-2017 used here are 15 (Granada), 18 (Potenza), 12 (Athens) and 6 (Limassol). For the region of Cyprus the situation is more complex since Middle East dust outbreaks occur frequently [13, 14]. Taking that into account, the selection of the Saharan dust events over Limassol should be handled with care.

Since pure dust layers $\left(\delta_{\mathrm{p} 532}=0.31 \pm 0.02,[15]\right)$ are rare over urban Mediterranean cities due to urban, polluted or even marine aerosols and their mixtures, a sufficiently lower $\delta_{\mathrm{p} 532}$ threshold value should be considered for long-range transported dust aerosol layers in our data set. The $\mathrm{LR}_{532}$ values are expected to range between 40 and $60 \mathrm{sr}$ with some exceptions/deviations.

Consequently, for the total set of dust events over each station, we considered for further analysis only cases that meet two basic criteria: i) the $\delta_{\mathrm{p} 532}$ to exceed 0.15 in the free troposphere and ii) the thickness of the detected layer to be $500 \mathrm{~m}$, at least. The critical height (in meters asl) in which the first criteria was met, was considered to be the base of the layer. This assumption was deemed necessary to be made since usually, the lofted dust layers cannot be distinguished from the top of the Atmospheric Boundary layer (ABL), while the presence of urban haze takes low $\delta_{\mathrm{p}}$ values $(0.03-0.10)$. The top of the dust layer was estimated as the height where the signals were similar to the molecular scattering in the free troposphere. For some cases of Athens station, where only Raman-Lidar measurements were available, the values of the base and top were calculated from the Lidar signals, following the procedure proposed by [11]. Thus, the number of the total cases of each station that fulfills the aforementioned criteria per optical property may differ (see Fig.2). For each case, mean $\delta_{\mathrm{p} 532}$, mean $\mathrm{LR}_{532}$ and mean $\mathrm{AOT}_{532}$ values were calculated inside the layers. The corresponding standard deviation (sd) values give an indication of the variability of these parameters from base to top within the layer.

Moreover, we performed a careful investigation of the air mass origin and long-range dust aerosol transport by means of backward trajectory analysis. This analysis was carried out using the HYbrid Single-Particle Lagrangian Integrated Trajectory (HYSPLIT) model (http://www.arl.noaa.gov /HYSPLIT.php).

\section{RESULTS}

\section{Statistics of the dust aerosol optical properties}

The backward trajectories from HYSPLIT per station are shown in Fig.1 revealing the origin of each observed layer. In the majority of the cases, air masses originate from the west and northwest Africa (Morocco, Mauritania, Algeria and Tunisia).

Fig.2 shows the mean values of the optical $\left(\delta_{\mathrm{p} 532}\right.$, $\mathrm{LR}_{532}, \mathrm{AOT}_{532}$ ) and geometrical (base, top, thickness) properties per station and per event. For all stations no large variations in the mean values of each parameter are observed with Granada to hold the minimum values for base and the maximum for top and layer's thickness. The mean $\delta_{\mathrm{p} 532}$ for Athens and Limassol is shifted a bit to higher values, while no remarkable variations in $L_{532}$ values were observed $(51 \pm 1 \mathrm{sr})$ among the four stations.

Based on the HSRL classification by [16] we plotted the intensive aerosol quantities, $\mathrm{LR}_{532}$ versus $\delta_{\mathrm{p} 532}$ (Fig. 3a), and we identified three of the six existing clusters in our data. Our first cluster (green marks/errorbars, green trajectories, Fig.3b) represents a mixing state of Saharan dust and BB aerosols.

Table 1: Institute, location and Lidar setup of the selected EARLINET stations providing data for this study.

\begin{tabular}{lllll} 
Station & Abbreviation & Location & Lidar setup & References \\
$\begin{array}{l}\text { Andalusian Institute for Earth System } \\
\text { Research, University of Granada, Spain }\end{array}$ & IISTA-CEAMA, & $\begin{array}{l}37.16^{\circ} \mathrm{N},-3.61^{\circ} \mathrm{E}, \\
\text { elev. } 680 \mathrm{~m}\end{array}$ & $\begin{array}{l}\text { MULHACEN } \\
3 \beta+2 \alpha+1 \delta(532 \mathrm{~nm})\end{array}$ & {$[17]$} \\
\hline $\begin{array}{l}\text { Consiglio Nazionale delle Ricerche }- \\
\begin{array}{l}\text { Istituto di Metodologie per l'Analisi } \\
\text { Ambientale, Potenza, Italy }\end{array}\end{array}$ & $\begin{array}{l}\text { CNR-IMAA, } \\
\text { Po }\end{array}$ & $\begin{array}{l}40.60^{\circ} \mathrm{N}, 15.72^{\circ} \mathrm{E}, \\
\text { elev. } 760 \mathrm{~m}\end{array}$ & $\begin{array}{l}\text { MUSA } \\
3 \beta+2 \alpha+1 \delta(532 \mathrm{~nm})\end{array}$ & {$[18]$} \\
\hline $\begin{array}{l}\text { Laser remote Sensing Unit, National } \\
\text { Technical University of Athens, Greece }\end{array}$ & LRSU-NTUA, & $\begin{array}{l}37.96^{\circ} \mathrm{N}, 23.78^{\circ} \mathrm{E}, \\
\text { elev. } 212 \mathrm{~m}\end{array}$ & $\begin{array}{l}\text { EOLE/AIAS } \\
3 \beta+2 \alpha+1 \delta(532 \mathrm{~nm})\end{array}$ & {$[19]$} \\
\hline $\begin{array}{l}\text { Cyprus University of Technology, } \\
\text { Limassol, Cyprus }\end{array}$ & CUT, & $\begin{array}{l}34.67^{\circ} \mathrm{N}, 33.04^{\circ} \mathrm{E}, \\
\text { elev. } 10 \mathrm{~m}\end{array}$ & $\begin{array}{l}\text { Polarisation Raman Lidar, } \\
1 \beta+1 \alpha+1 \delta,(532 \mathrm{~nm})\end{array}$ & {$[20]$} \\
\hline
\end{tabular}



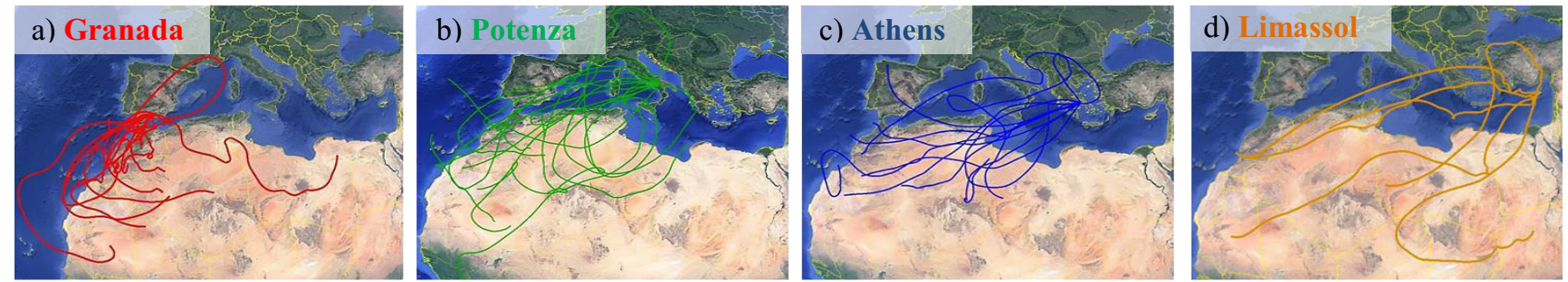

Figure 1: 96-120 hour backward trajectories over a) Granada, b) Potenza, c) Athens and d) Limassol, for arrival heights of approximately the center of each layer of all selected cases from the period 2014-2017.

a)
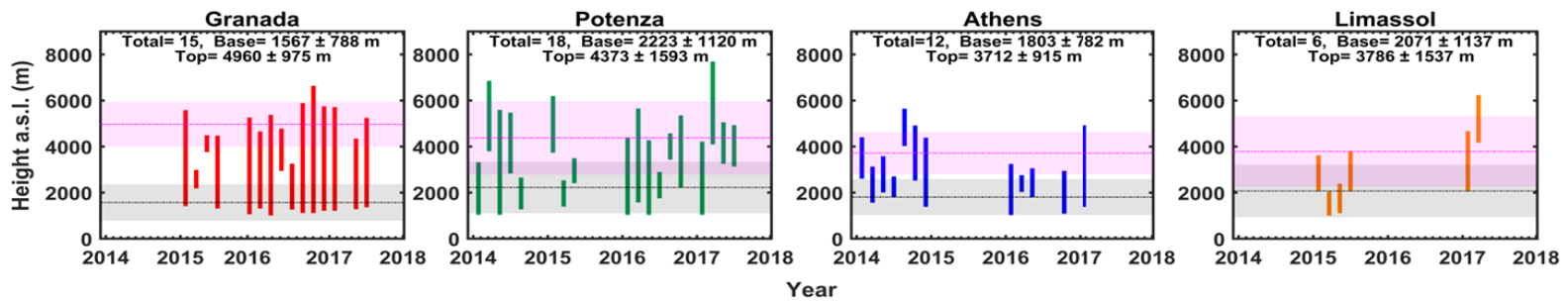

b)
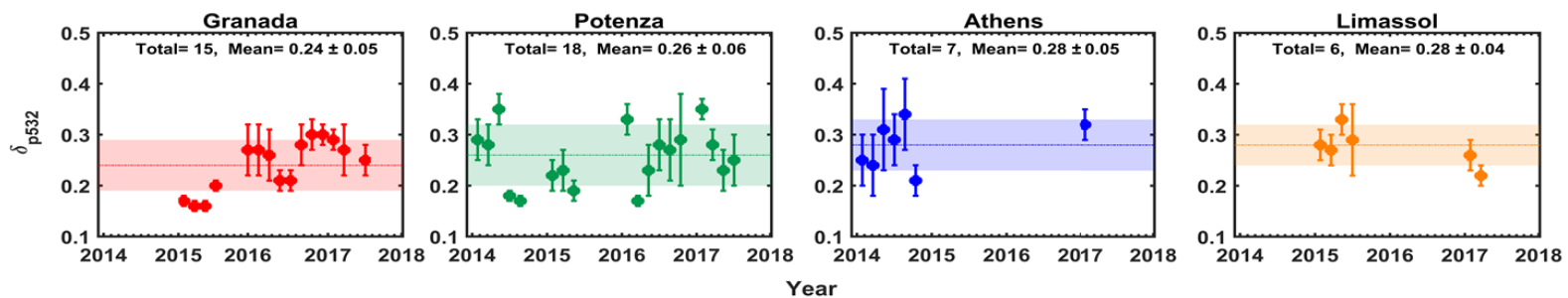

c)
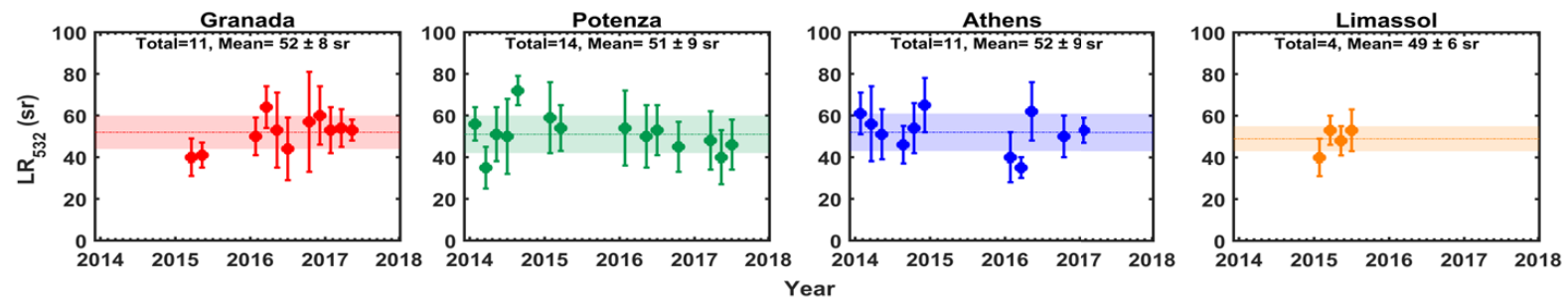

d)
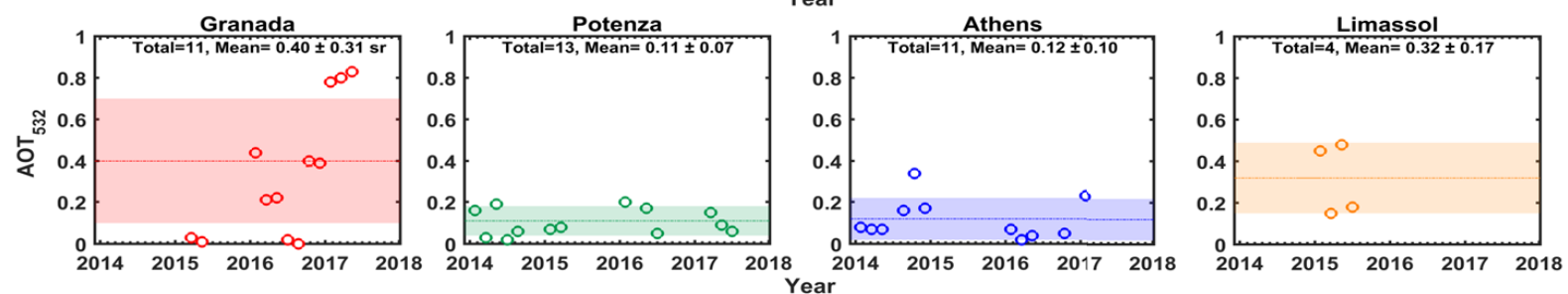

Figure 2: Mean values of a) base and top, b) $\delta_{\mathrm{p532}}$, c) $\mathbf{L R}_{532}$ and d) $\mathrm{AOT}_{532}$, per station (text and banded lines) and per case (symbols), along with their sd (error bars) inside the observed dust layers.

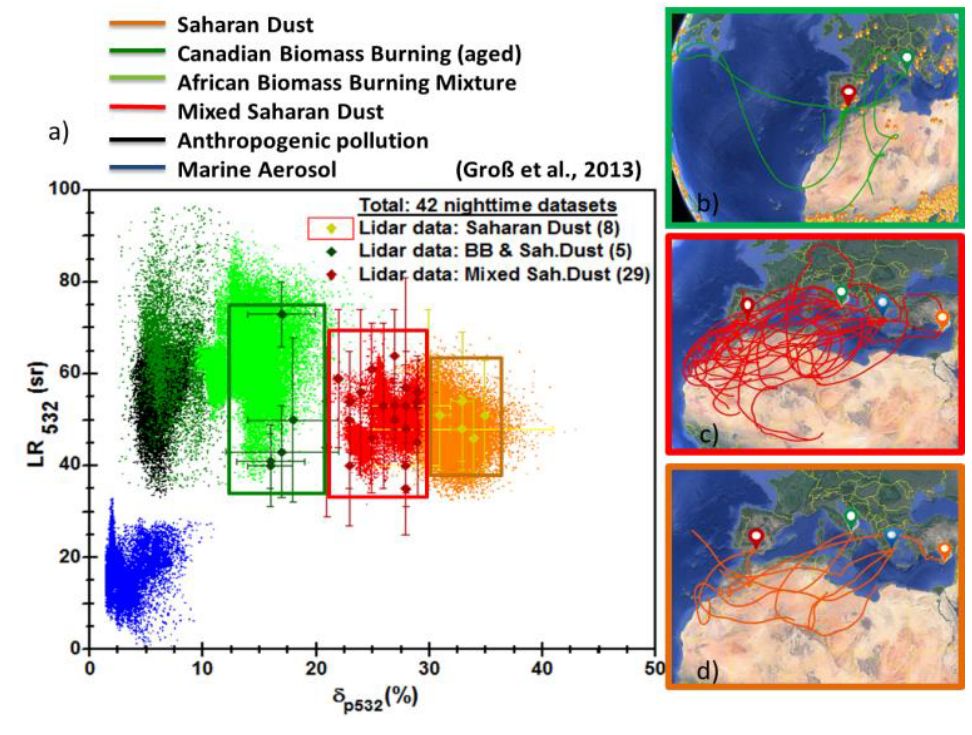

Figure 3: a) $L R_{532}$ vs. $\delta_{\mathrm{p} 532}$ from HSRL observations (colored dots) along with the selected datasets from the four EARLINET stations (symbols and error bars) b) backward trajectories for BB \& Saharan dust (green) cluster c) backward trajectories for mixed Saharan dust (red) cluster and d) backward trajectories for Saharan dust (orange) cluster.

The second cluster (red marks/errorbars, red trajectories, Fig.3c) is attributed to mixed Saharan dust, where dust aerosols are dominant, but BB, urban or marine aerosols are also possibly present. The third cluster (orange marks/errorbars, orange trajectories, Fig.3d) is in good agreement with former findings of pure Saharan dust layers $[15,16]$.

The 29 of the 42 datasets fulfill the specifications of the mixed dust cluster, as air masses are usually circulating over Mediterranean and Europe (and 
Turkey for Limassol cases) (Fig.3c), while the 8 cases corresponding to the Saharan dust cluster seem to travel shorter paths, in time and distance, before reaching the observation stations. The rest 5 seem to have a clear influence of BB aerosols not only from Africa but also from Canada (Fig.3b, with inserted fire information from MODIS, https://firms.modaps. eosdis.nasa.gov). As expected, the air masses of the
Saharan dust cluster have higher mean $\delta_{\mathrm{p} 532}$ and $\mathrm{AOT}_{532}$ values, larger layers' vertical thickness (m) and less mixing hours $(26 \pm 13 \mathrm{~h})$ after leaving African continent in comparison with the mixed Saharan dust cluster $(66 \pm 41 \mathrm{~h})$ and the BB \& mixtures cluster $(41 \pm 26 \mathrm{~h})$. No clear conclusions can be extracted from the parameter $\mathrm{LR}_{532}$ (see Fig.4).

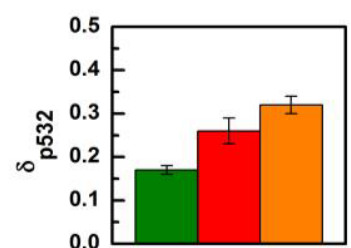

a)

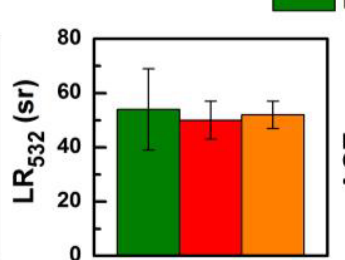

b)

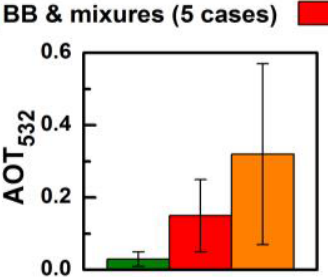

c) Clusters

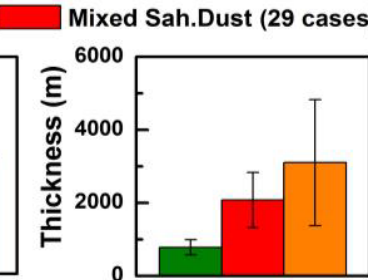

d)

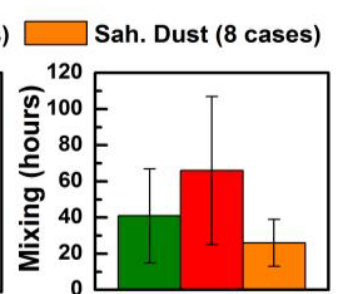

e)

Figure 4: Mean values of a) $\delta_{\mathrm{p532}}$, b) $\mathbf{L R}_{532}$, c) $\mathbf{A O T}_{532}$, d) thickness and e) mixing hours (after leaving African continent) for the three identified clusters.

\section{CONCLUSIONS}

A total of 51 cases of Saharan dust events observed over 4 southern Europe cities were studied with regard to their optical and geometrical properties. Backward trajectory analysis allowed for source identification of the elevated Saharan dust layers over the Mediterranean region. The dust layers are usually observed between $\sim 1.6$ and $\sim 5 \mathrm{~km}$. $\delta_{\mathrm{p} 532}$ and $\mathrm{LR}_{532}$ values range from 0.16 to 0.35 and from $35 \mathrm{sr}$ to $73 \mathrm{sr}$ respectively, depending on the mixing state. Significantly high AOT $_{532}$ values were found for Granada indicating that the dust outbreaks occurred over this area are more intense. Results of $\mathrm{LR}_{532}$ vs. $\delta_{\mathrm{p} 532}$ are presented in order to elucidate the difference of dust and dust with mixtures. Layers with lower $\delta_{\mathrm{p} 532}(0.17 \pm 0.01), \quad \mathrm{AOT}_{532}$ $(0.03 \pm 0.02)$ and thicknesses $(786 \pm 212 \mathrm{~m})$ indicate high mixing ratio, while the properties of the least or no mixed dust layers $\left(\delta_{\mathrm{p} 532}=0.32 \pm 0.02\right.$, $\mathrm{AOT}_{532}=0.31 \pm 0.23$ and thickness $=3158 \pm 1606 \mathrm{~m}$ ) are in a good agreement with literature findings for pure Saharan dust. LR seems to be less effective in extracting conclusions about the mixing state of a layer, possibly due to the same absorption efficiency of BB and dust.

\section{ACKNOWLEDGMENTS}

O. S.'s research project has been financed through a scholarship from the General Secretariat for Research and Technology (GSRT) and the Hellenic Foundation for Research and Innovation (HFRI).

\section{REFERENCES}

[1] P. Salvador, et al. Atmos. Chem. Phys. 14, 67596775. doi.org/10.5194/acp-14-6759-2014 (2014)

[2] F. Barnaba and G. P. Gobbi, Atmos. Chem. Phys., 4, 2367-2391. www.atmos-chem-phys.net/4/2367/2004/ (2004)
[3] A. Papayannis, et al. Journal of Geophysical Research, VOL. 113, D10204. doi:10.1029/2007JD009028 (2008)

[4] O. Soupiona, et al. Atmos. Environ. 183, 165-174. doi.org/10.1016/j.atmosenv.2018.04.011 (2018) [5] A. Nisantzi, et al. Proc.Volume 8182, SPIE Remote Sensing, 818217. doi:10.1117/12.898357 (2011)

[6] E. Flaounas, et al. 2015. Atmos. Sci. Lett. 16, 473478. doi.org/10.1002/asl.584 (2015)

[7] IPCC. Cambridge University Press, pp. 571-658. doi.org/10.1017/CBO9781107415324.016 (2014)

[8] D. Balis, et al. Geophys. Res. Lett. 31, 10-13. doi.org/10.1029/2004GL019881 (2004)

[9] I. Mattis, et al. Geophys. Res. Lett. 29, 20-21. doi.org/10.1029/2002GL014721 (2002)

[10] L. Mona, et al. Adv. Meteorol. Vol. 2012, Article ID 356265, 36 pages. doi.org/10.1155/2012/356265 (2012)

[11] L. Mona, et al. J. Geophys. Res. Atmos. 111, 1-13. doi.org/10.1029/2005JD006569 (2006)

[12] M. Tesche, et al. Tellus B Chem. Phys. Meteorol. 63, 649-676. doi.org/10.1111/j.1600-0889.2011.00548.x (2011)

[13] S. Solomos, et al. Atmos. Chem. Phys. 17, 40634079. doi.org/10.5194/acp-17-4063-2017 (2017) [14] P. Kokkalis, et al. MDPI, Remote Sensing, 10, 1807, doi.org/10.3390/RS10111807 (2018)

[15] V. Freudenthaler, et al. Tellus, Ser. B Chem. Phys. Meteorol. 61, 165-179. doi.org/10.1111/j.16000889.2008.00396.x (2009a)

[16] S. Groß, et al. Atmos. Chem. Phys., 13, 2487-2505. doi.org/10.5194/acp-13-2487-2013 (2013)

[17] J.L. Guevrrero-Rascado, et al. Atmos. Environ. 42, 2668-2681. doi:10.1016/j.atmosenv.2007.12.062 (2008) [18] F. Madonna, et al. Atmos. Meas. Tech., 4, 11911208 doi:10.5194/amt-4-1191-2011 (2011)

[19] P. Kokkalis, et al. $26^{\text {th }}$ ILRC, June 25-29, 2012, Porto Heli, Greece. (2012)

[20] A. Nisantzi, et al. Atmos. Chem. Phys., 15, 70717084. doi:10.5194/acp-15-7071-2015 (2015) 